
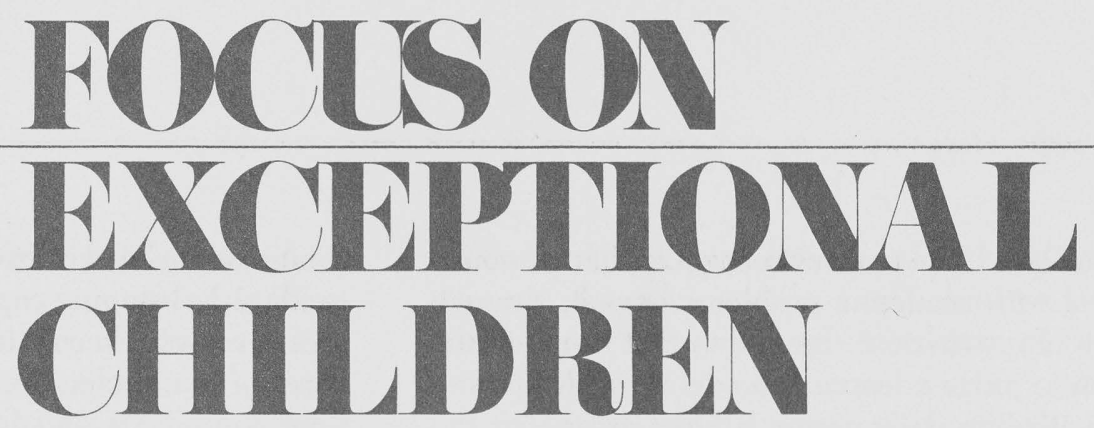

\title{
THE TEACHER'S ROLE IN REFERRAL FOR TESTING AND INTERPRETATION OF REPORTS
}

TEACHER'S ROLE IN THE REFERRAL PROCESS

\author{
Mary Ross Moran ${ }^{1}$
}

Over the past few years, the proliferation of diagnostic services made available to classroom teachers has increased the complexity of decisions they must make about assessment. They are asked to determine whether referral is indicated, who should be asked to test a student, and how results can be evaluated to make instructional decisions. The following discussion represents an attempt to organize the teacher's task.

Bases for decision are discussed in two parts. Part I, the Teacher's Role in Referral, describes three levels of assessment, from academic performance through psychomotor, cognitive, and affective evaluation, offering suggestions for appropriate referral at each level, followed by guidelines for formulating useful referral questions and for preparing a student for referral. Part II, the Teacher's Role in Interpretation, outlines three types of statements to be found in reports and offers suggestions for evaluating each type. A brief concluding section explores the attitudes to be cultivated by the teacher who would benefit from the referral process.

Although some suggestions are incorporated for the testing to be conducted by the classroom teacher, the focus of this discussion is upon decisions about referral and interpretation of testing conducted by other professionals. A more comprehensive approach to the process of teacher diagnosis and programing within the classroom is provided elsewhere (Moran, 1975).

\section{THE TEACHER'S ROLE IN REFERRAL}

The basic question for any teacher is whether to rely upon her own assessment of a student's strengths and weaknesses or to refer the learner for evaluation by other professional specialists. The question is a serious one, and it requires a great deal of careful thought on the part of the teacher.

1. Dr. Moran is Assistant Professor, Department of Special Education, University of Kansas Medical Center, Kansas City, Kansas.

(C) Love Publishing Company 1976 
On the one hand, the teacher recognizes her responsibility to deal with academic problems herself, through modification of instruction; she knows that she is in the best position to judge a learner's academic skills because she works with him daily across subject areas. On the other hand, the teacher is aware that lowered academic performance can be a secondary symptom of underlying cognitive, perceptual, emotional, social, or medical problems which she is not trained to evaluate. How is she to decide which student can be adequately assessed in the classroom and which one requires the services of specialists?

This decision is never simple, but it can be aided by considering different levels of assessment. There are at least three levels of assessment which could be distinguished.

\section{ACADEMIC FUNCTIONING LEVEL}

On the surface level, the level which might be called Academic Functioning Level, a learner's academic strengths and weaknesses in each subject area can be identified and grade levels of achievement computed.

\section{Sample Statements}

This is the level at which it is reported that third-grader Joe has the following academic characteristics: "Indepen-

FOCUS ON EXCEPTIONAL CHILDREN is published monthly except June, July, and August as a service to those concerned with mentally retarded and emotionally disturbed children. This journal is abstracted and indexed in Exceptional Child Education Abstracts, and is also available in microfilm from Xerox University Microfilms, Ann Arbor, Michigan. Subscription rates, $\$ 10.00$ per year. Copyright 1976, Love Publishing Company. All rights reserved. Reproduction in whole or part without written permission is prohibited. Printed in the United States of America. Second class postage is paid at Denver, Colorado.

$$
\begin{gathered}
\text { Executive and Editorial Office } \\
6635 \text { East Villanova Place } \\
\text { Denver, Colorado } 80222 \\
\text { Telephone (303) } 757-2579
\end{gathered}
$$

\section{EDITORIAL BOARD}

Edward L. Meyen University of Kansas
Glenn A. Vergason Georgia State University

Richard J. Whelan

University of Kansas Medical Center

Sallie Carmachel Keeney

Managing Editor Stanley F. Love
Publisher dent reading level is Primer, instructional reading level is grade 2-1, listening capacity level is grade $3-1$. Lowest scores on word recognition skills tests occurred on measures of sound blending, recognizing the visual forms of final consonants and blends, double vowels, and dipthongs. Overall grade level in math is $2-2$, with lowered scores on place value, missing elements, and geometric forms. Spelling grade level is $2-0$. Spelling is marked by omission of endings, b-d confusion, and inaccurate spacing of letters, with some correct letters in transposed order. Handwriting rate is scored at a grade level of 1-6. Manuscript letters are of uneven size with irregular spacing."

\section{Typical Descriptors}

Descriptors which might be used at this first level of assessment include grade level, grade equivalent, percentile, stanine, score, skill level, test profile, diagnostic test results, criterion level, mastery level, trial teaching.

\section{Representative Tests}

Of course, careful inspection of the child's daily written products and observation of his task behavior must be

\section{STATEMENT OF OWNERSHIP, MANAGEMENT AND CIRCULATION}

Date of Filing: September 30, 1976

Title of Publication: FOCUS ON EXCEPTIONAL CHILDREN

Frequency of Issue: Monthly except June, July and August

Location of Known Office of Publication: 6635E. Villanova Place, Denver, CO 80222

Location of Headquarters of Publisher: 6635 E. Villanova Place, Denver, CO 80222

Name and Address of Publisher, Editor, and Managing Editor: Stanley F. Love, 6635 E. Villanova Place, Denver, CO 80222

Owner: Stanley F. Love

Extent and Nature of Circulation:

$\begin{array}{cc}\begin{array}{c}\text { Average No. Copies } \\ \text { Each Issue during } \\ \text { Preceding 12 months }\end{array} & \begin{array}{c}\text { Single Issue } \\ \text { Nearest to } \\ \text { Filing Date }\end{array} \\ 7,833 & 8,000 \\ & \\ 0 & 0 \\ 6,407 & 6,997 \\ 6,407 & 6,997 \\ 500 & 500 \\ 6,907 & 7,497 \\ 926 & 503 \\ 7,833 & 8,000\end{array}$

$\begin{array}{lrr}\text { Total No. Copies Printed } & 7,833 & 8,000 \\ \text { Paid Circulation } & 0 & 0 \\ \quad \text { Sales thru Dealers, etc. } & 6,407 & 6,997 \\ \quad \text { Mail Subscriptions } & 6,407 & 6,997 \\ \text { Total Paid Circulation } & 500 & 500 \\ \text { Free Distribution } & 6,907 & 7,497 \\ \text { Total Distribution } & 926 & 503 \\ \text { Office Use and Left Over } & 7,833 & 8,000 \\ \text { Total } & \quad \text { I certify that the statements made by me above are correct and complete. }\end{array}$

I certify that the statements made by me above are correct and complete.
(Signed) Stanley F. Love, Publisher 
considered in addition to any special testing which is done at this level, because these factors carry strong implications for educational planning. At this level of assessment, some test instruments are appropriate, apart from the standardized group achievement tests which are always part of the classroom record. Individual testing may be conducted using an informal reading inventory constructed from the classroom series, the Classroom Reading Inventory (Silvaroli, 1973), a graded reading test such as the Standard Reading Inventory (McCracken, 1966), or the Diagnostic Reading Scales (Spache, 1963). If they have been trained in standardized procedures, teachers can and do use gross screening instruments such as the Peabody Individual Achievement Test (Dunn \& Markwardt, 1970) or diagnostic instruments such as the Keymath (Connolly, Nachtman \& Pritchett, 1971). Some teachers prefer the detailed skills information which can be obtained from measures such as the Basic Educational Skills Inventory (Adamson, Shrago \& Van Etten, 1972). Recently, more teachers are developing their own criterion-referenced tests based upon classroom materials, or they are making systematic observations and records of a child's responses to trial teaching-two approaches which have proved particularly effective for individualized planning. All of the aforementioned approaches to obtaining a description of the child's academic performance are available to the regular classroom teacher, and she is in the best position to assess a child at this level. Even if it is determined that further evaluation is necessary, any child who is referred to a school psychologist or other ancillary personnel should first be assessed at this descriptive level by the classroom teacher. No one else can assess this level better than the teacher who has unlimited samples of the child's task behavior, written products, and the opportunity to carry out individual testing, observation, and trial teaching over time.

\section{Considerations for Referral}

There are a few situations in which a teacher might refer questions at this first level of assessment to other professionals. The special reading teacher, for example, might be asked to carry out some individual reading evaluations such as the Durrell Analysis of Reading Difficulty (Durrell, 1955) or the Gates-McKillop Reading Diagnostic Tests (Gates \& McKillop, 1962) for youngsters whose reading problems have resisted the classroom teacher's efforts at diagnosis and remediation. An itinerant learning disabilities teacher or a resource room teacher might be asked to assist in diagnosis of skills deficits if the classroom teacher is not satisfied that she has enough description of a child's relative strengths and weaknesses to plan an individual program for a specific student. The curriculum supervisor of reading or math might be consulted for recommendation of specific approaches to instruction to solve a specific problem.

But questions which can be resolved at the Academic Functioning Level are not appropriate for referral to a school psychologist, counselor, or clinical psychologist. Such personnel are not curriculum specialists, they are not specially trained in materials selection, and they are seldom in a position to make useful recommendations in regard to specific instructional practices. If the question concerns establishment of reading levels, skills levels in word recognition, comprehension, spelling, computation, numerical reasoning, writing, or other academic skills, the screening instruments widely used by psychologists, such as the Wide Range Achievement Test (Jastak \& Jastak, 1965) or the Peabody Individual Achievement Test (Dunn \& Markwardt, 1970), yield data too gross to be of diagnostic assistance to teachers in instructional planning; time lost in waiting for such test results will only delay the teacher's own assessment of these skills.

\section{PSYCHOMOTOR OR PROCESS FUNCTIONING LEVEL}

At the second level of assessment, which might be called the Level of Psychomotor or Process Functioning, sensory awareness is checked, modality preference or learning style can be established in terms of ability to work better with auditory or visual cues, and many of the perceptual and expressive subskills which are presumed to underlie academic skills can be inferred. It is beyond the scope of this article to discuss the advantages and disadvantages of testing psychomotor abilities or what research has said about the relevance of such testing to educational programing. Although testing of psychological process dimensions is discouraged by the research literature, one has only to observe school testing situations or inspect record folders to determine that such testing is being done and that educational decisions are being made on the basis of such test results. Indeed, some state mandates for special educational services have been written in such a way that testing of psychological correlates such as visual and auditory discrimination, memory, sequencing, and other subskill constructs must be reported for funding purposes. Decisions about whether or not such testing would be appropriate must be made according to local standards and philosophy. Because test- 
ing at this level is controversial, it will be discussed in greater detail than the first and third levels.

\section{Sample Statements}

This is the level of functioning which could be described by statements such as the following: "John's pattern of scores and test behavior indicated strengths in auditory discrimination, sequencing, closure, short-term auditory recall, and verbal skills. Performance items which required visual organization, with or without a model, revealed relative weaknesses in revisualization, spatial relationships, and directionality. These weaknesses account for John's difficulty in writing and spelling."

\section{Typical Descriptors}

Descriptors which might be used to identify characteristics at this level of functioning include visual acuity, form discrimination, figure-ground distinction, form constancy, visual closure, revisualization, visual sequential memory, eye-hand coordination, dexterity, laterality, directionality, discrimination of spatial relationships, body image, tactile or kinesthetic discrimination, auditory acuity, discrimination of sound, auditory figure-ground distinction, reauditorization, auditory sequential memory, auditory closure, speech articulation.

\section{Representative Tests}

Instruments used for second-level evaluation usually are those which isolate auditory, visual, and motor components of tasks, such as the Illinois Test of Psycholinguistic Abilities (Kirk, McCarthy \& Kirk, 1968), Purdue Perceptual Survey Rating Scale (Roach \& Kephart, 1966), Bender Visual-Motor Gestalt Test (Bender, 1938), Lincoln-Oseretsky Motor Development Scale (Sloan, 1954), Templin-Darley Tests of Articulation (Templin \& Darley, 1960), Goodenough-Harris Drawing Test (Harris, 1963), and Southern California Perceptual-Motor Tests (Ayres, 1968).

The administration of such instruments of evaluation is usually considered to be the province of the trained psychologist, speech clinician, physical or occupational therapist, or a special educator with psychometric training. If such tests are determined to be needed, they should be used by one especially trained to administer and interpret them. Most tests at the second level of assessment would not be appropriate for administration by a regular classroom teacher. There may be exceptions, however. If a teacher decides that she wishes to do her own second-level assessment, some standardized tests are available to her.

As long as administration and scoring standards are rigidly followed, many people would agree that instruments such as the Developmental Test of Visual-Motor Integration (Beery \& Buktenica, 1967), the Motor-Free Visual Perception Test (Colarusso \& Hammill, 1972), or the Diagnostic Auditory Discrimination Test (Goldman, Fristoe \& Woodcock, 1974) can be appropriately used by classroom teachers. Although considerable experience with these tests is required to establish a clinical basis for inferences to be drawn from them, the scores can yield some useful information about how a given child performs these tasks under controlled classroom conditions. If most students in the classroom can successfully respond to the quiet subtest of the auditory discrimination test, for example, but Sally falls below the 10th percentile, this information is corroboration of classroom observation of this learner's difficulty with phonics instruction. This test result may be enough to encourage a teacher to engage in trial teaching of a more visual approach or a word-family approach to reading; the use of this test in a classroom can be justified for such a purpose.

The use of the test cannot be justified, however, if the teacher intends to make inferences from the test about Sally's "auditory discrimination" skills in general. No single test can be the basis for such an inference, and statements made about visual or auditory skills on the basis of any single instrument are certain to be misleading. This is why a school psychologist or clinician uses a battery of tests. As there is generally some degree of overlap of indicators in different tests, the presence of a single indicator provides the basis for a hypothesis which must be confirmed by additional indicators on other tests before a statement can be made about the auditory or visual skills of a given learner.

Although a classroom teacher may use some standardized tests for the purpose of confirming classroom observation, she is by no means limited to this method of obtaining further data at the Psychomotor or Process Level of assessment. By the use of informal test procedures, carefully designed and observed, a teacher can gain considerable information about a child's visual, motor and auditory subskills. Informal, teacher-made test procedures lack the precision of standardized tests, but they have the advantage of permitting the free substitution of stimulus and response modes which is impossible under standardized conditions. For example, if the student cannot write spelling words to dictation, the teacher can isolate the cause of such a problem by asking the student to spell the same words orally, then to select a correctly spelled word from a group of four minimally 
contrasted alternatives, and finally to copy the spelling words from printed cards. If all these procedures are followed, it should be possible to say with some certainty whether Johnny's problem with spelling is due to breakdown of auditory, visual, or motor components.

In addition to the advantage of alternative stimulus and response modes, informal teacher-made tests at the second level of assessment have the advantage of a firm relationship to terminal classroom behaviors. That is, a teacher who is assessing a child in a classroom to determine subskills is more likely to assess auditory functions by using curriculum materials such as a phonics worksheet, for example, than by asking a child to repeat digits. For this reason, results of such assessment are likely to be more directly interpretable into classroom practices. In contrast, many of the tasks of the ITPA (Illinois Test of Psycholinguistic Abilities) or the Ayres battery, for example, are so far removed from classroom tasks that it is difficult for most teachers to see any relevance of scores on those tasks to classroom work.

\section{Considerations for Referral}

Before one can talk of visual or auditory perception, it must be determined that the student has adequate sensory information to be processed. Therefore, any question of the student's visual or auditory sensory intactness should have high priority for referral. The school nurse usually performs only a Snellen chart screening and an audiometric sweep check; therefore, consultation might be sought with an orthoptic specialist, optometrist or opthalmologist, the district hearing conservationist or a clinical audiologist.

Behavioral information which should lead a teacher to suspect a defect in vision might include covering one eye while reading or looking at the blackboard; moving a book or paper back and forth in the line of vision as if to bring it into focus; persistent rubbing of the eyes; closing eyes or resting forehead on arm frequently while reading; jerking or quick movement of the pupil of the eye; complaints of eye fatigue, double or blurred vision, chronic headaches.

Behavioral symptoms of possible hearing problems might include turning the head toward the direction of sound; lack of response to speech originating behind the learner; unusually close attention to the mouth of a speaker; requests for repetition of instructions when conditions are noisy or the pupil is farther from the teacher than usual; severe articulation problems, including omission of many consonant sounds, especially ending sounds such as $/ \mathrm{t} /$ and $/ \mathrm{s} /$; lack of response to phonics instruction, despite adequate instruction with a variety of methods over a period of time. Many of these symptoms are likely to be displayed by children with chronic and severe throat or upper respiratory infections, asthma, or allergies affecting the respiratory system.

If a child displays a cluster of these behaviors, or even one or two with frequency and consistency, a teacher should refer the child for sensory evaluation before considering other types of evaluation. If there are indications of such deficit, the results of academic or psychological testing cannot be adequately interpreted until sensory deficit has been ruled out.

At the second level of assessment, many professional persons might be consulted, other than the school psychologist or counselor. If there is a question of gross motor problems, a physical therapist might be asked to work with the physical education instructor to develop a modified program. If fine-motor skills are underdeveloped or uneven, an occupational therapist might be asked to offer suggestions for appropriate pencil-andpaper activities. If articulation is markedly delayed, the speech clinician should be asked to evaluate the student. When second-level assessment is required, therefore, the teacher has a number of resources for assistance.

When a teacher refers a student for evaluation by a school psychologist or clinical psychologist, second-level assessment which takes place can frequently provide useful insights into a student's learning style. An experienced clinician can draw inferences about the student's strengths and weaknesses in terms of processes which cannot be directly observed, are difficult to isolate due to confounding or overlapping of task dimensions, and involve psychological constructs which are difficult to validate. The experience of the person drawing the inferences is critical - the same information can frequently be interpreted in more than one way, and a given battery of tests can result in conflicting information which must be reconciled in order to make meaningful statements about a student.

When should a referral be made for second-level assessment by a school or clinical psychologist? If the teacher has observational data to support a suspicion that Johnny demonstrates a specific severe perceptual or expressive deficit; if the teacher has attempted to gain further information herself by trial teaching and is not satisfied with what she has found; if Johnny is failing to profit from the instruction which the teacher has deemed suitable; and if the teacher is convinced that she cannot program effectively for the child without additional information on his subskills and most favorable learning style, or has reason to believe that he may require special services, then a referral for such testing is appropriate. 
A referral for evaluation at this second level is not appropriate if the teacher is merely curious about whether the student may demonstrate some type of "learning disability." Such a determination is not enough to provide the basis for instructional programing. If testing of psychomotor processes establishes that Johnny is primarily a visual or auditory learner, or that a developmental lag in fine-motor skills explains his writing problems, these insights are worth having only if they lead the teacher to design an individual program for the student. Too frequently, a referral is made to determine "if there is a specific learning disability," and subsequent information is never incorporated into daily programing for the child.

Because many teachers lack confidence in their own ability to describe their students' learning characteristics, they make many referrals for process testing when they already have, or could obtain from classroom procedures, the information they need to do effective programing. If third-grader Johnny has not mastered manuscript printing, the teacher has a problem in instructional programing. If a psychologist's standardized tests establish that the problem is due to developmental lag in visual-motor integration skills, the teacher still has the same instructional programing problem. The psychologist's analysis of reversals and rotations on the Bender will not tell the teacher how to instruct the child any more than will her own observation of the student's attempts to write his name. In fact, the name-writing task, which is closer to the desired terminal behavior, is likely to yield more useful information. The teacher should be concerned about the child in the classroom because he cannot write, not because he cannot draw geometric figures. Referral for psychomotor or process testing should be considered, therefore, only if the teacher is prepared to translate such information into instructional practices. Instead of considering referral for second-level testing by a school psychologist, the teacher might consider requesting an inservice program on interpreting informal test results into methods and materials for instruction.

\section{COGNITIVE AND AFFECTIVE FUNCTIONING LEVEL}

The third level of assessment could be called the level of Cognitive and Affective Functioning. At this level, only a well-trained and experienced clinician is in a position to make statements about a student. The cognitive and affective characteristics of a given student can be discussed separately, of course, but they are combined here because they are considered to operate on the same level of abstractness and because they interact to some degree. A cognitive component might be described, for example, as the learner's ability to organize a plan of operation before beginning a motor task, but the affective component would be his willingness to delay movement and inhibit impulse in order to engage in preplanning. There is also some degree of overlap between the cognitive and psychomotor domains, but they have been separated for purposes of this discussion.

\section{Sample Statements}

At the third level of assessment, statements similar to the following might be made: "Johnny is currently functioning in the borderline range of intelligence. Test behavior as well as significantly lowered performance on tasks requiring concentration indicate that failure to achieve academically may be due to interference by emotional factors such as anxiety or intrusive thoughts. Verbal abilities such as categorization and association are at a low average level. Adaptive social behavior is age-appropriate and rules out the possibility that Johnny should be recommended for placement in an EMR classroom."

\section{Typical Descriptors}

Descriptors which may be used in the cognitive domain include analysis, synthesis, association, classification, deductive and inductive reasoning, problem-solving, prediction, and evaluation. Descriptors which may be used in the affective domain include attention, deliberation, compliance, effort, autonomy, inhibition, constriction.

\section{Representative Tests}

Tests which are appropriate to yield level three assessment are individual IQ measures such as the Wechsler Intelligence Scale for Children (Wechsler, 1974), the Stanford-Binet Intelligence Scale (Terman \& Merrill, 1973), Leiter International Performance Scale (Arthur, 1952; Leiter, 1940), Nebraska Test of Learning Aptitude (Hiskey, 1966), and projective measures such as the Thematic Apperception Test (Murray, 1943) or the Rorschach Psychodiagnostic Plates (Rorschach, 1954). None of these are appropriate for use by the regular classroom teacher.

The reason for reserving assessment at the third level to experienced clinicians is that this is the level which most frequently is the basis for administrative decisions on delivery of special services or placement in special educa- 
tion classes. Because administrators are rightfully being made more accountable for such decisions, it is imperative that those providing data on which such decisions are made be carefully trained and experienced examiners.

\section{Considerations for Referral}

How does a teacher know when she should refer a student for cognitive or affective evaluation? If the student's social skills are those of a younger child and if he requires an unusual number of trials to master a task, it may be useful to request evaluation of level of intellectual functioning so that classroom expectations can be realistic or special instruction arranged. If a student's achievement is so far above that of others in the class that the teacher suspects that he should be in a special accelerated program, testing may be needed to confirm such a placement. If a learner's day-to-day academic and social performance is so inconsistent that classroom observation and trial teaching do not answer questions about the child's academic and behavioral strengths and weaknesses, evaluation at the third level is indicated. If a student is typically withdrawn from peer and teacher contact or if acting-out behavior does not respond to classroom intervention over time; if a student engages in cruel or aggressive acts without remorse; if a learner consistently complains of vague physical illnesses and uses such complaints to avoid classroom tasks-in these situations referral for evaluation is indicated.

From a teacher's point of view, cognitive evaluation should not be necessary simply because the level of intellectual functioning is not known. If the teacher can program for the student so that he can respond to instruction, the IQ is probably irrelevant. Similarly, referral is not justified because there may be evidence of family conflict or situational emotional stress. Unless battering is suspected, the teacher's responsibility in such matters is to see to it that her own contacts with the child are always therapeutic. She cannot alter a parent's plan for divorce, for example, by confirming through testing that the child is not functioning academically because of emotional stress. However, a sharp change in academic or social behavior without evidence of any situational disturbance to account for it may be reason to consult with the counselor or school psychologist for evaluation of cognitive or affective functioning.

\section{Guidelines for Referral Questions}

Many teachers may react to these statements about appropriate levels of assessment with the question, "How can I control the type of evaluation which is conducted when I just refer a child to the psychologist, and I never know what kind of testing he will do?" The answer to that question is this: If a teacher writes an appropriate referral question, only the testing which answers that question should be conducted. School psychologists and other professionals would much prefer to focus their testing on specific questions rather than take a "shotgun" approach to evaluation. If irrelevant testing is reported while the teacher's questions about instructional planning remain unanswered, it may be because the teacher has not communicated effectively with the person to whom the student has been referred for testing.

What are the elements of an effective referral question? First, a good referral question is accompanied by all information already available to the teacher. It cannot be stressed too strongly that a teacher who refers a student must know everything that can be learned about him under classroom conditions before she should even consider referring the learner to someone else for testing.

It is totally inappropriate, for example, for a teacher to refer a student for evaluation of visual or auditory subskills involved in the reading process without simultaneously reporting to the potential examiner the student's instructional reading level, scores on skills tests in reading, and information about the student's level of vocabulary and grammar. If a teacher refers a child as a reading problem without providing the test information she already possesses, she cannot be surprised if the testing does not go beyond what she had already discovered. All relevant classroom test scores, behavioral observations, and reports of daily written products should be presented in summary form as part of the referral.

Second, the teacher should always report as part of a referral any intervention which she has already attempted with this student. For example, if she has conducted trial teaching of a VAKT (Visual-Auditory-Kinesthetic-Tactile) method of presenting sight words and has found it ineffective, she should report that information; otherwise, she is likely to find that the examiner will recommend just that procedure for the learner whose visual skills are relatively weak. Any special materials or methods which have been tried, and the length of time they have been applied, should be mentioned. Also, the textbooks and supplementary materials currently being used with the student should be listed. If the classroom operation includes a system of rewards or a token economy, that information should be provided so that any recommendation for intervention would be made within that framework. If these types of information are provided, the teacher should not find, as so many have reported, 
that the examiner has suggested interventions which had already been undertaken.

Third, the teacher must make a statement of what she has to know in order to instruct the student appropriately. That is, she has to be able to state what it is about the student that she cannot discover in the classroom. In the case of a reading problem, for example, she should be able to state that she would like to know whether Johnny demonstrates the subskills to profit from group reading instruction in the strongly phonics-oriented basal reader, or whether auditory skills are markedly below norms for his age. She may want to ask if Johnny's failure to complete written seatwork appears to be due to behavioral causes or deficient fine-motor skills. She may suspect that a student is unusually bright, and she wants to know how far she should push the child to achieve and how he can best be motivated since he is not now achieving. If the question is one of placement, it should be so stated: Does Johnny require individualized instruction in a small group situation such as a resource room or self-contained special class? Is Jim a candidate for placement in an EMR classroom on the basis of his difficulty in keeping up with the lowest groups in the class? Should Sally have reading instruction in the resource room but remain in the classroom for all other instruction?

Beyond the obvious benefits in terms of communication with the person to whom the student is referred, a teacher's close attention to these three components of a good referral question will clarify for the teacher her own goals and programs for a given student. If every teacher would discipline herself to compile this information-a list of academic achievement levels in each subject area; statements about word-recognition and comprehension reading skills, arithmetic computation skills, arithmetic reasoning skills, writing and spelling skills; comprehensive reports of all materials and methods which have been attempted with the student; precise questions about what the teacher needs to know about the childshe would probably find that she could answer many of her own instructional questions without referral. For those questions which she could not answer, she would be providing the basis for straightforward answers from a school psychologist or other ancillary personnel which would be more likely to solve her instructional programing difficulties.

\section{GUIDELINES FOR PREPARING A STUDENT FOR REFERRAL}

If the results of testing conducted by other professionals are to be of maximum usefulness to the teacher, testing should be conducted under optimal conditions. The teacher cannot control the selection of the testing room, the examiner's ability to establish rapport, or the noise from the playground. But she can, and should, attempt to motivate the student to cooperate with test procedures and develop a positive set for working at his best.

Motivation for testing is highly dependent upon the student's perception of the purpose of the evaluation, the assurance that he will learn the outcome of testing, and some understanding of the use to which test results will be put. Regardless of the child's age, he deserves a straightforward explanation of why the teacher is asking someone else to test him. The teacher might say, for example, "Jim, I can't figure out why you have so much trouble doing phonics worksheets with the class and I've asked someone else to try to help me find a way to make it easier for you." Or she might say, "I don't know how much work it is sensible to give you; I've asked someone else to help me find out how much you can handle."

The student deserves some assurance that he will receive feedback about the test results. It is astonishing how many teachers believe that the results of testing are the concern of administrators and parents, but never consider that such results should be the concern of the testee himself. Even a first grade child can understand test results at some level, and he should have a simple explanation of the findings. A teacher might say, for example, "After you have seen Mr. Jones, he will tell me what you did and then I will talk to you about it so you and I can decide which work is best for you." A child cannot be expected to care about his performance if he is never to know the outcome of the testing or how test results will be used to make decisions.

A student gains a positive work set largely from knowing that he is expected to work and from being told something about the tasks he will be asked to perform. This does not mean that test items are to be described in advance. Even if the teacher knows the exact tests to be administered, which she probably does not, it would invalidate any standardized test to describe tasks in detail. Instead, what is required is a set of statements which tell the child that he will probably be asked to answer some questions, use a pencil and paper, and put some things together with his hands. The teacher might add: "Some of the tasks will be like the ones you do in school, and some will be very different. Some will be too easy for you, perhaps, and others will be harder. What we expect you to do is just the very best you can."

It is a mistake to tell the student, as some teachers have done, that the session will consist of "playing games with Mr. Jones." If the student enjoys the tasks, that is to the advantage of all concerned; but he should not enter a 
testing situation with an expectation of games rather than work.

A young child who is unprepared for testing can find the experience bewildering or anxiety provoking. An older student may believe that something is terribly wrong with him if no one is willing to discuss the reasons for testing, and he may react with self-depreciation and hostility toward the adults who placed him in this position.

The teacher's responsibility to prepare a student for referral is part of her overall task of making the student a full partner in a cooperative undertaking-meeting educational objectives. If the teacher-learner relationship is to be cooperative rather than competitive, the student must view the process as a series of joint decisions toward mutual goals. He becomes a partner by being consulted about major steps in the process, by being offered reasons for actions to be taken, and by enlisting his support for the referral rather than imposing it upon him. A teacher who is willing to devote time and effort to preparing a student for referral will not only benefit from valid and useful test results, she will participate in humanizing the educational process.

\section{THE TEACHER'S ROLE IN INTERPRETATION}

After the decision has been made to refer a student for evaluation by a school psychologist, counselor, or clinical psychologist, the next problem to be faced by the teacher is how to interpret the subsequent report in ways that will help her implement the findings. The comprehensiveness and quality of reports vary so greatly among examiners that it is very difficult to state any generalizations about the document which the teacher will receive. With few exceptions, however, and regardless of the length of the report, it should contain three types of statements: Information, Inferences, Judgments. Although there is some overlap, these three types of statements are not to be confused with the three levels of assessment described above. All three statement types occur at each of the three levels of assessment.

\section{INFORMATIONAL STATEMENTS}

Statements which quantify behavior (such as "John earned a full-scale IQ of 95 , a verbal IQ of 90 , and a performance IQ of 102 " or "Scores on all visual perception tasks were within normal limits for his age" or "John computed twelve two-digit addition facts in two minutes") or statements which report test behavior in observable terms (such as "John used his left hand for drawing and writing tasks") are statements which can be called Information. The chief characteristic of Information is that it is verifiable; that is, independent scorers and independent observers should reach a high level of agreement on statements if they are to be labeled Information statements.

If disputes about Information statements arise, it is possible to go to the test record forms or to a videotape of the testing session and resolve any dispute by reference to the observable facts. It is possible for Information to be inaccurate, as when an examiner applies the wrong table in translating raw scores to standard scores, but accurate Information cannot truly be disputable-it is subject to direct verification. Because Information is factual, it must be the basis upon which the other two types of statements are made.

\section{INFERENTIAL STATEMENTS}

The second type of statement always found in a report is an Inference, a statement made about the unknown on the basis of the known. Statements which would be classified as Inference are, for example: "Deficits in visualmotor integration skills are the basis for Jim's inability to complete written seatwork" or "Jim's test behavior is that of a dependent child who could be expected to function better in a one-to-one or small group setting than in a large group."

Inferences are not directly verifiable-that is, they are not factual. Instead they are interpretations of facts. There will not, therefore, be as high a degree of agreement between independent observers about Inferences as about Information. For example, two Inferences"Jane demonstrated negative behavior throughout the test" and "Jane lacks self-confidence when faced with an unfamiliar task" - could both be based upon the same observation, that Jane did not attempt eight of ten subtest items in one test. Depending upon additional behaviors which Jane exhibited, either of these Inferences might be correct, and one would have to go to the test behavior to determine clusters of behavior which support negativism and those which support lack of self-confidence.

Inferences are thus documented by the massing of behavioral indicators to support alternative interpretations. The accuracy of Inferences depends upon the training and experience of the examiner. Inferences drawn by a conscientious, well-trained, and experienced examiner are likely to be accurate and useful; those drawn by a careless, poorly trained, or inexperienced examiner may be little more than conjecture. 


\section{JUDGMENTAL STATEMENTS}

The third type of statement to be found in a report is a Judgment, which is a decision about what action should be taken. Typically, Judgments in a report are the recommendations-for example, "Jim's level of intellectual functioning, adaptive social behavior, and emotional status indicate that he is appropriate for placement in an EMR classroom" or "Joe would profit from a multisensory approach to reading instruction which would allow him to compensate for inadequate visual memory" or "Mary requires an intervention program in the classroom to motivate her to complete work without teacher aid."

Judgments are based upon Inferences, which are in turn based upon Information; therefore, Judgments are twice removed from fact, and error is subject to a compounding effect. Any Judgment can be only as sound as the Inferences and Information upon which it is based.

\section{INTERACTION OF INFORMATION, INFERENCES, AND JUDGMENTS}

An example of statements at each of these levels about the same child will clarify the relationships among the types of statements. The recommendation, "Bob should be placed in a primary learning disabilities resource room for daily instruction in both reading and mathematics," is a Judgment. It is based upon the following Inferences:

"Bob demonstrates a language deficit which affects his ability to manipulate symbols; he lacks skills in revisualization, spatial relationships, directionality, and visual sequencing. He has average intellectual potential, but learning is limited by inadequate language and organization of visual information. Bob is also handicapped by overreliance on teacher aid, and he lacks the independent study and social skills to function effectively in a large group for instruction." These Inferences are, in turn, based upon information such as the following:

"Bob earned a full-scale IQ of 93, a verbal scale of 80 , and a performance scale of 111. Vocabulary and Similarities subtest scores were below the mean of other verbal scores. Bob did not carry out a sequence of two oral directions. Picture Completion and Coding subtests, as well as Bender reproductions, were below the norms for his chronological age and below his mean scores for other performance items. Bob stopped twice during pencil and paper tasks to ask for examiner aid; he also requested examiner aid on two out of three manual manipulation tasks. When a model was pre- sent, visual-motor tasks were completed with greater speed but rotations and inversions of direction still occurred. When the examiner demonstrated a visualmotor task, Bob asked for a repetition of the demonstration, then carried it out in an order the reverse of the model."

When a Judgment is supported by such detailed observations, it is possible for the teacher to determine easily if the Judgment is documented. But it often happens that only the recommendations are stated-Information and Inference statements are sometimes omitted from brief reports. This is only one of the possible problems which can be encountered by a teacher who is a critical reader of reports.

\section{INTERPRETATION OF INFORMATIONAL STATEMENTS}

Statements which can be termed Information represent factual material. Yet, Informational statements require some interpretation by the teacher who must be able to take into account error in measurement, differences in frame of reference for observations, and the distinction between observation and interpretation.

\section{Error in Measurement}

There is error in any measurement, regardless of the factor to be quantified or the skill of the examiner. There are at least two reasons for such error. First, any sample of behavior at a specific time is subject to situational and environmental variables; second, any test is at best only a sample of the possible tasks which could measure a specific skill or process, and a different set of items could produce different results.

Therefore, the teacher should not interpret data reported in Information statements as absolute scores; instead, any score should be thought of as an estimate of the range of the student's ability on any given dimension rather than a discrete point. This range is best considered in terms of the standard error of measurement, which is a statistic supplied by the test publisher to describe the possible variations in the scores of a single individual if he took the test a number of times or took alternate forms of the test. Standard error is a band of probable inaccuracy on either side of the observed score. If the standard error of measurement for a given test is 3.6 for example, there is a probability of about two-thirds that a specific student's true score is within a range of 3.6 above or below the obtained score; for a score of 95 , there is a high probability that the true score, if it could be determined, would lie 
between 91.4 and 98.6 .

The fact that a child's true score can only be estimated is not justification to dismiss scores on standardized tests as useless because they are not precise. When an examiner uses a standardized test, at least he knows how much margin for error should be allowed, and he can draw his Inferences accordingly. We have no similar margin for error computed in regard to other possible bases for decisions - such as observation of daily work products, for example. Therefore, as long as test scores are considered to represent a band or range and as long as the examiner has used a valid and reliable instrument, criteria for which are beyond the scope of this article, test scores provide useful Information.

It is important for a teacher to make a distinction between recognizing the limitations of test scores and disregarding scores altogether. It sometimes happens that a teacher decides to dismiss test scores reported by another examiner because such scores do not agree with the teacher's own observations of the student. If the teacher has an impression, for example, that Bob's vocabulary is quite adequate in conversation, she may want to dismiss a test score which indicates that vocabulary is far below age norms.

Once a teacher has decided that she needs information about a student which could be answered by testing and once she decides to proceed by referring the child to a school psychologist, she is not then free to disregard the test results simply because she does not agree with them. In fairness to the student, all test results should be considered; if there are discrepancies between test scores and the teacher's observations, those discrepancies should be resolved rather than test scores dismissed.

\section{Frame of Reference for Observations}

Problems arise when a teacher who was not present for the evaluation reads the observations of the examiner and finds that the learner described in the report is different from the student known to the teacher. This can happen because teacher and examiner view the child under different conditions and from different points of view.

The teacher sees the student in a group, doing academic work, and in familiar surroundings. The teacher is usually concerned primarily with the way in which this individual fits into the classroom groupings, and she will note whether he is developmentally similar to other third graders she has taught. The examiner sees the student on a one-to-one basis, performing unfamiliar nonacademic tasks, under timing and stress, working with a comparative stranger. The examiner has been trained to observe subtle differences between individuals; use of standardized instructions and tasks elicits minor differences in response.

If a student is described differently from the way the teacher sees the learner, does this mean that the observations of the examiner are irrelevant to the classroom? On the contrary, problem-solving approaches of preplanning or trial and error, response sets of deliberation or impulsive guessing, initiative or dependence demonstrated in the testing situation can suggest intervention strategies in the classroom. The important thing is that the teacher consider the implications of different behavior in the testing situation. If the student performed better, the teacher should ask whether he might be more responsive to one-to-one tutoring by a peer or an aide in the classroom; whether he requires more variety in tasks rather than limiting him to texts and workbooks; whether her own or the group's interaction with the child may be anxiety-provoking in the classroom. If the child performed less well in the testing situation, the teacher should ask what implications this has for the student's ability to cope with a different volunteer aide every day, with new instructional material, and with other changes in daily routine or personnel.

As long as the statements cover observable behavior, it is not reasonable for a teacher to take exception to the task behavior which is reported. The student may not appear that way to her, but she must accept the reality that the student behaved that way in the testing situation. Differences in the learner's behavior under the two conditions should then become the subject for discussion between examiner and teacher so that useful intervention approaches can emerge from insights about the student's task behavior.

\section{Distinction Between Observation and Inference}

Differences in frame of reference for observations can be identified by the thoughtful teacher, but problems which arise because an examiner has confused observations with interpretations of behavior are much less likely to be recognized even by the careful reader.

It is very difficult for many examiners to state Information rather than Inferences. A statement such as "Jim became angry when he could not assemble the fourth block design" is an Inference. The Information statement would read, "Jim worked on the fourth block design for 30 seconds without reproducing it; he then destroyed his attempt by overturning the blocks." It requires considerable skill and a great deal of self-discipline for an examiner to report observations as opposed to interpretations of 
what was observed. Statements of behavioral observations should be read critically to determine whether interpretation is included. A teacher should ask: Is that observable, or would the examiner have to go beyond observation to make that statement? Is that behavior, or has the statement gone beyond behavior to report feeling state or attitude of the student? Words which are likely to describe observable behavior are those which involve action, such as "Joe pointed to correct items rather than naming them" or "Joe kicked the chair leg repeatedly throughout the ten-minute subtest," as opposed to Inferences which might be stated as "Joe did not know the labels for common household items," or "Joe was tense throughout the ten-minute subtest."

\section{INTERPRETATION OF INFERENTIAL STATEMENTS}

When the examiner states Inferences, the teacher must check those Inferences against the weight of the supportive evidence and against previous experience with the same examiner. Since the accuracy of Inferences is dependent upon the training and experience of the examiner, which the teacher is in no position to judge, the teacher needs some method of attempting to validate Inferences. The teacher usually will wish to do so when the report lacks Information statements, when Inferences appear to go beyond the evidence of Information statements, or when Inferences appear to contradict test scores.

\section{Lack of Information}

If the teacher receives only the examiner's interpretations and recommendations without test scores or behavioral observations, she may question the accuracy of Inferences which do not agree with her own experience with the student. In such case, she should request the original test record sheets. If the examiner is willing to supply them, the test records considered with the report may answer the teacher's questions. If not, or if the examiner does not provide the record sheets, the teacher should request a conference with the examiner.

If the examiner's Inferences do not accord with the teacher's experience with a student, it is not enough for the teacher to say so and dismiss the report. Instead, she should examine the responses to test items. She may find that the examiner's statement that Bill is far below average in verbal problem-solving is well documented despite her observation that Bill is highly verbal and always the first to raise his hand to answer a question. It is precisely this type of hidden deficit that may be revealed by standardized testing, and it is important that the teacher remain open to new data about a student.

There is a difference, however, between being open to new Information and being willing to accept Inferences without Information. The teacher is justified in requesting documentation for Inferential statements contained in reports.

\section{Statements Beyond Information}

If scores and test behavior are included in the report yet Inferential statements appear to be stronger than the evidence warrants, the teacher is also justified in requesting documentation. The usual explanation for such an occurrence is that the examiner had access to data which he did not compile himself. Sometimes, a student has had prior school district testing which the teacher has not seen. In other cases, a student has been evaluated at a community clinic without the teacher's knowledge.

If such reports are available to the examiner but not to the teacher, the result can be apparent discrepancies between the examiner's data and his Inferences. A good examiner will draw his Inferences from all available Information, and he would be wrong to disregard prior testing. But if such testing is not mentioned, the teacher cannot evaluate the Inferences. The teacher should request a conference with the examiner to discuss the basis for any statements which are not supported by the reported test data.

\section{Statements Contradicting Scores}

The Inferences which are usually most troublesome to teachers in reading reports are those which appear to contradict the reported scores. An examiner may report, for example, that verbal skills are strong, yet the teacher notes that three out of five verbal scores were far below the mean for other subtests. There are two possible explanations for such an occurrence.

The basis for inferring strengths might be the quality, as opposed to the quantity, of the responses. For example, it sometimes happens that because of test anxiety a student may miss easy items on the standardized test but respond correctly to much more difficult items. He will be penalized in scoring, but the level of his accurate responses will indicate his ability on the dimension being measured. The examiner bases his interpretation upon the individual responses, not just the overall score.

Another explanation may lie in the examiner's consideration of test behavior or situational problems during 
testing. The examiner may be able to say, for example, that visual-motor integration skills are well within normal limits, even though scores on three out of five performance items are significantly lowered. The student may have lost points because he did not look at the model, overdeliberated, or waited for examiner aid. If the examiner is satisfied that the items which were completed demonstrated adequate skills, the lowered score can be explained by the inappropriate test behavior.

In a comprehensive report, the examiner should include statements which reconcile test behavior with test scores so that the interpretation is clear. If this has not been done, a phone call or conference can clarify the Inference.

\section{INTERPRETATION OF JUDGMENTAL STATEMENTS}

Because recommendations which evolve from evaluation are the purpose of referral, Judgments about actions to be taken are the most important statements in the report. They are also the most difficult to interpret, since they are often far removed from fact. In a well-reasoned report, the Judgments flow from Inferences, which flow from Information; and there is a consistent, logical progression. In a less well-organized or overly brief report, Information or Inferences may be misplaced or omitted.

If Information is missing, it can be requested as suggested above. When Inferences are not presented, however, it is more difficult for the teacher to isolate the source of discrepancy. But missing Inferences are not the only problem with interpretation of Judgments. The more common problem seems to be that recommendations are not stated in instructional terms.

\section{Lack of Inferences}

If a teacher receives only test data and recommendations, her problem is one of organization. She has the task of determining which test scores are related, and placing scores in groups on the basis of different kinds of relationships. Test behavior must also be organized to determine how the child's approach to tasks bears upon the recommendations.

The teacher will know that Inferences are missing if she does not find statements such as "Jack is functioning intellectually in the low-average range despite scattered scores in the borderline range" or "Pam is limited academically by fine-motor skills three years below her mental age." Such Inferences should support the action the examiner recommends. If they are missing, it is a formidable task to supply them.
The difficulty of the task is, though, only one reason to avoid leaving this responsibility to the reader of the report. Because Inferences must be drawn from the interaction of the demands of the task, the student's problem solving approaches and the situational conditions, it is essential that the person who states Inferences has observed the child throughout the testing session. For example, the same low score earned by two different students on a timed subtest such as the Coding section of the Wechsler Intelligence Scale for Children (Wechsler, 1974) must be interpreted differently if one student went right to work on the task, maintained attention, and worked continuously throughout the time limits, while the second child dropped his pencil once, looked around the room twice, and paused for several seconds within the time limits. The examiner is able to take such behaviors into account when drawing Inferences; one who was not present cannot evaluate the total test behavior even with extensive notes.

The burden of organizing Information in order to draw Inferences rests, then, upon the examiner so the teacher need not take that responsibility upon herself. If a report does not contain them, a teacher is justified in requesting summary statements about the student's strengths and weaknesses so that they can be considered in relation to the recommendation.

\section{Omission of Procedures}

A common complaint of teachers who refer students for testing is that the report merely identifies the problem areas but does not tell the teacher how to instruct the child. For example, the recommendation "Lisa's visual deficits and relative auditory strengths should be considered in designing reading instruction" leaves many questions for the teacher. Does this mean that she needs a strong phonics approach? If so, does she require a synthetic phonics method? Which series could she use? Which supplementary materials? Should she receive instruction on tapes? Can she use worksheets?

A different type of recommendation "Joe's motivational problems require a behavior intervention program which should be coordinated between his classroom and his home" elicits just as many questions. Should he be placed on a contract? How about a daily report card with good work to be rewarded at home? What will he consider a reward? How can the parents best be involved? What are the priority behaviors to be targeted for change?

There may be a number of reasons why recommendations in reports are not stated in step-by-step procedural terms. One reason is that many training programs for school psychologists and counselors do not include inten- 
sive coursework in instructional methods and materials. Consequently, some examiners are not well enough acquainted with the possible options to be able to suggest specific instructional practices.

Even if the examiner is a former classroom teacher, suggestions for implementation may not be included for another reason-teachers do not always react favorably when examiners offer specific plans or programs. If the examiner makes recommendations so specific that they can be followed in cookbook fashion, many teachers react negatively to their limited involvement in the planning as they feel that their role is being usurped. If detailed procedures contain one or two suggestions which could not be implemented in a specific classroom because of space or materials limitations, a teacher may dismiss the entire package as "impractical." If the examiner suggests ways to individualize instruction in several academic areas, a teacher may protest that time pressures and 30 other students make implementation impossible. Such responses by teachers are understandable, but they lead to a dilemma on the part of the examiner who may be able to offer specific suggestions but has learned from experience that some teachers do not welcome instructional recommendations.

If a teacher prefers to design her own program for implementing recommendations involving classroom instruction, she will probably find that the general recommendations usually found in reports will suffice for her purposes. She may have access to curriculum specialists, a materials retrieval center, or special education teachers who could help her with modification of procedures or materials.

If a teacher genuinely welcomes specific suggestions for instruction or nonacademic intervention, she would be wise to ask for detailed recommendations when she forwards the referral questions. If detailed procedures are not then provided, she should request a conference with the examiner so that she can ask questions about possible alternative ways to implement the recommendations. She will nearly always obtain useful ideas from such an exchange, and the examiner may be more willing to offer specific suggestions the next time one of her students is evaluated.

It is part of the teacher's role to communicate to an examiner what she hopes to gain from the referral. The examiner, the student, and the teacher will all profit from such a frank statement of expectations.

\section{TEACHER'S ATTITUDE TOWARD REFERRAL AND INTERPRETATION OF REPORTS}

A teacher is required to make many decisions about the instruction of each student assigned to her. In some cases, measurement of the student's behaviors will help her to make those decisions. If behaviors or conditions which are interfering with response to instruction can be identified by referral to diagnostic specialists, both the teacher and the student will benefit. The teacher's orientation toward the referral process and the implementation of recommendations is crucial. To obtain the greatest benefit from the referral process, a teacher might consider adopting the following points of view.

\section{Accept the Psychometric Orientation.}

When a teacher decides that she cannot answer her instructional questions about a student through classroom procedures and she refers the student for testing, she makes certain commitments to the psychometric approach. She must orient her thinking toward the comparison of that child with other children. This type of comparison is considered to be inappropriate by some teachers, who prefer to judge a student against absolute standards rather than norms. But the teacher cannot have it both ways. She cannot at the same time obtain the information she requires from standardized tests and choose to ignore the normative data.

Once the psychometric approach has been taken, test scores cannot be disregarded if the examiner considers them valid. Although it may be tempting for a teacher to do so, she is not justified in permitting her subjective appraisal of the student to supercede test data; instead, the two views of the student should be reconciled.

\section{Consider Yourself a Member of a Team.}

When differing views of a student must be reconciled, it is important that the teacher feel free to confer with the examiner, the principal, and other professional personnel who work with the student. Only if members of the team view themselves as co-professionals - each with unique but equal skills to offer-can they disagree constructively or resolve apparent differences about courses of action.

Respect for the expertise of a fellow professional sometimes comes more readily to a teacher than does respect for her own expertise. Some teachers may defer to the decisions of a psychologist, for example, out of awe at the mystique of specialized knowledge which teachers do not have, without recognizing the value of their own understanding of the learning process and their access to unlimited samples of the student's behavior. Women teachers may defer to fellow professionals who are men, because acculturation has led them to consider the male 
voice as the voice of authority. Such orientations are not compatible with a team concept.

At the other extreme, some teachers may consider that they are the only ones who can make decisions about students assigned to them. Too many examiners have had the experience of accepting a referral from a teacher, testing, writing a report and recommendations, only to learn that the teacher has not implemented any of the examiner's suggestions nor requested a conference with the examiner to discuss any areas of disagreement. This type of passive rejection of the work of a fellow professional is seriously damaging to the referral process and unfair to the student who deserves to have all available information considered before decisions are made about him.

\section{Respect Confidentiality of Reports.}

When a teacher considers herself a professional team member, she recognizes that test scores, task behaviors, summaries of functioning levels, and statements about the student's needs are appropriately discussed only with members of the team or with the student's parents. Statements drawn from reports are not shared casually in the teacher's lounge.

In addition to the responsibility to avoid verbal publication of test findings, a teacher is expected to exercise care over the disposition of the written report. Placing a report among the student's graphs or charts may permit a volunteer parent aide to gain access to it. Leaving a report exposed upon a desk may mean that another student will see test scores or summary statements. Inadvertent exposure to aides, peers, or nonprofessional school staff may mean that a student's status will be inappropriately discussed.

\section{Maintain Realistic Expectations.}

Even though a teacher constructs sound referral questions and the examiner conducts a comprehensive assessment, it is too much to expect that instructional preblems can always be solved by referral. For stubborn instructional dilemmas, testing will prove less useful than systematic trial teaching over time; for daily programing, the teacher's own assessment is essential to answer questions of materials selection, sequencing, and pace. The availability of diagnostic specialists does not limit the teacher's responsibility for instructional decisions. Referral to specialists is merely one possible recourse available to the classroom teacher who recognizes her final responsibility for establishing instructional objectives and implementing individualized programs to meet those objectives.

\section{REFERENCES}

Adamson, G., Shrago, M., \& Van Etten, G. Basic educational skills inventory. Olathe, KS: Select-Ed, 1972.

Arthur, G. The Arthur adaptation of the Leiter International Performance Scale. Washington, DC: Psychological Service Center Press, 1952.

Ayres, J. Southern California perceptual-motor tests. Los Angeles: Western Psychological Services, 1968.

Beery, K., \& Buktenica, N. Developmental test of visual-motor integration. Chicago, IL: Follett, 1967.

Bender, L. Bender visual-motor Gestalt test for children. New York: American Orthopsychiatric Association, 1938

Colarusso, R., \& Hammill, D. Motor-free visual perception test. San Rafael, CA: Academic Therapy, 1972.

Connolly, A. Nachtman, W., \& Pritchett, E. Keymath diagnostic arithmetic test. Circle Pines, MN: American Guidance Service, 1971.

Dunn, L., \& Markwardt, F. Peabody individual achievement test. Circle Pines, MN: American Guidance Service, 1970.

Durrell, D. D. Durrell analysis of reading difficulty. New York: Harcourt, Brace \& World, 1955

Gates, A., \& McKillop, A. Reading diagnostic tests. New York: Teachers College Press, 1962.

Goldman, R., Fristoe, M., \& Woodcock, R. Diagnostic auditory discrimination test. Circle Pines, MN: American Guidance Service, 1974.

Harris, D. B. Goodenough-Harris drawing test. New York: Harcourt Brace Jovanovich, 1963.

Hiskey, M. S. Nebraska test of learning aptitude. Lincoln, NE: Marshall S. Hiskey, 1966.

Jastak, J. F., \& Jastak, S. R., Wide range achievement test. Wilmington, DE: Guidance Associates, 1965.

Kirk, S., McCarthy, J., \& Kirk, W. Illinois test of psycholinguistic abilities. Urbana, IL: University of Illinois Press, 1968.

Leiter, R. G. Leiter international performance scale. Santa Barbara, CA: Santa Barbara State College Press, 1940.

McCracken, R. A. Standard reading inventory. Klamath Falls, OR: Klamath Printing Company, 1966.

Moran, M. R. Nine steps to the diagnostic-prescriptive process in the classroom. Focus on Exceptional Children, 1975, 6, 1-14.

Murray, H. A. Thematic apperception test. Cambridge, MA: Harvard University Press, 1943.

Roach, E. G., \& Kephart, N. C. Purdue perceptual survey rating scale . Columbus, OH: Charles E. Merrill, 1966.

Rorschach, L. G. Rorschach psychodiagnostic plates. New York: Grune \& Stratton, 1954.

Silvaroli, N. Classroom reading inventory. Dubuque, IA: W. C. Brown Company, 1973.

Sloan, W. Lincoln-Oseretsky motor development scale. Chicago, IL: Stoelting, 1954.

Spache, G. Diagnostic reading scales. Monterey, CA: McGraw-Hill, 1963.

Templin, M., \& Darley, F. The Templin-Darley tests of articulation. Iowa City, IA: Bureau of Educational Research and Service, State University of Iowa, 1960.

Terman, L. M., \& Merrill, M. A. Stanford-Binet intelligence scale. Boston, MA: Houghton-Mifflin, 1973.

Wechsler, D. Wechsler intelligence scale for children-revised. New York: Psychological Corporation, 1974. 


\section{CLASSROOM} FORUM

Edited by Melinda Young Special Education Specialist Vanderlyn Elementary School Dekalb County, Georgia than merely point or demonstrate in response to a question.

The teacher can also assist the hearing impaired child in many ways.

1. Seat the child six to ten feet away so that she may see your mouth as well as hear your voice distinctly. Make a standing rule that the child has permission to move when she cannot see or hear.

2. Foster the child's independence by making the child responsible for hearing. Let the child ask you to repeat directions rather than asking the child if she understands.

3. Give precise, clear oral instructions. Decide how you are going to expain something before you begin. Make the explanation short and to the point. Numbering or lettering the sequence of directions adds an additional cue. (First, take a sheet of paper; second, fold it in eight sections; third, illustrate the sequence of the story.)

4. Intersperse periods of peak hearing with freer times. Require the child to listen to directed teaching only for a short time. Then allow the child to complete a visual task, or play a game, read, etc.

5. Ask for some response on the part of the child. After giving oral instructions, ask the child to explain part of the instructions, demonstrate the directions, or follow through motorically.

6. Make your mouth clearly visible when speaking. Stand with the light source in front of you so that your face is not in shadow. Try not to obstruct your mouth with your hands.

7. Use a visual or tactual as well as an oral presentation when introducing new concepts. Use chalkboard demonstrations, self-discovery with manipulatives, pictures, and written explanations until the child understands the new concept. Then withdraw the visual or tactual cues so that the child must rely on her auditory channel alone for understanding. 